\section{REGENERACIÓN URBANA EN LA CIUDAD DE MÉXICO: POLISEMIA DE CONCEPCIONES Y DE ACCIONES PÚBLICAS}

Víctor Delgadillo ${ }^{1}$

\section{Resumen}

Este artículo analiza el uso del concepto de regeneración urbana en la teoría y la praxis en la Ciudad de México, usado desde la década de 1970 por distintas corrientes teóricas, políticas e ideológicas para confrontar los multidimensionales problemas económicos, sociales, físicos y medioambientales del deterioro urbano y del tejido urbano existente. El artículo evidencia que bajo este concepto se promueve y aplica una polisemia de acciones públicas (no neutras ni despolitizadas) y algunas iniciativas sociales para confrontar muy parcialmente diversos problemas urbanos.

\section{URBAN REGENERATION IN MEXICO CITY: POLYSEMY OF CONCEPTIONS AND PUBLIC ACTIONS}

\section{Abstract}

This article analyzes the usage of the term urban regeneration in the theory and the practice in Mexico City, which since the 1970s different theoretical, political, and ideological currents have used to address the multidimensional economic, social, physical, and environmental problems of urban decay and deterioration in the existing urban fabric. The article provides evidence that under this conception a polysemy of public actions (non-neutral or depoliticized) and some social initiatives are promoted and applied in dealing with very partially diverse urban problems. The article analyzes 
El artículo analiza experiencias de intervención pública realizadas, entre 1970 y 2020, en tejidos urbanos consolidados de la capital mexicana que fueron promovidos con mayor o menor intensidad por colectivos sociales en céntricos barrios populares, en el centro histórico y en barrios autoconstruidos en periferias urbanas. Más allá del discurso neutro de la regeneración urbana y de supuestas intervenciones integrales, en la práctica se continúan impulsando políticas sectoriales o negocios inmobiliarios que, pese a converger en un mismo territorio, no son integrales ni coordinadas ni benefician a la mayoría de la sociedad. El artículo recoge resultados de diversas investigaciones sobre las políticas urbanas y habitacionales en áreas urbanas realizadas en las últimas dos décadas.

PALABRAS CLAVE: REGENERACIÓN URBANA; ÁREAS URBANAS CENTRALES; POLÍTICAS URBANAS; CIUDAD DE MÉXICO.

Recibido: 2020-04-01

Aceptado: 2020-08-10 experiences of public interventions carried out between 1970 and 2020 in consolidated urban fabrics in Mexico's capital city, promoted with more or less intensity by social collectives in working-class neighborhoods downtown, the historic center, and self-built quarters in the urban periphery. Beyond the neutral discourse of urban regeneration and alleged comprehensive interventions, in the practice sectoral policies or real estate ventures that, although sometimes converge in a single territory, and are not comprehensive nor coordinated or do not necessarily benefit the majority of society. The article collects the results of various investigations carried out in the last two decades on urban and housing policies in different urban areas.

KEYWORDS: URBAN REGENERATION; INNERCITY AREAS; URBAN POLICIES; MEXICO CITY.

Received: 2020-04-01

Accepted: 2020-08-10

Colegio de Humanidades y Ciencias Sociales, Universidad Autónoma de la Ciudad de México, México, http://orcid.org/0000-0001-5928-6179. Correo electrónico: victor_delgadill@hotmail.com 


\section{Introducción}

Regeneración urbana es un concepto polisémico que en su origen aludía a confrontar los multidimensionales problemas económicos, sociales, físicos y medioambientales del abandono, vaciamiento y deterioro de las áreas urbanas centrales. Sin embargo, después se han incluido áreas fabriles obsoletas, puertos abandonados, estaciones de ferrocarriles y barrios periféricos, planificados o autoconstruidos. Así, actualmente, la regeneración urbana se asocia a la intervención de los tejidos urbanos existentes, sin importar su ubicación geográfica o su origen histórico. Regeneración es un concepto tomado de las ciencias naturales, que en urbanismo significa el restablecimiento de las funciones urbanas perdidas, la recreación de las actividades económicas, la mejora de la calidad de vida de los residentes y usuarios, y la reutilización de los barrios subutilizados o abandonados, preservando y aprovechando las estructuras edilicias existentes. Este artículo: indaga en el origen americano y europeo del concepto; demuestra que este concepto ha sido igualmente utilizado por diversas corrientes ideológicas y políticas; revisa brevemente algunas experiencias europeas de regeneración urbana que, con distintos nombres, se convirtieron en hito en Latinoamérica, y analiza experiencias de regeneración urbana en la Ciudad de México que, desde la década de 1970, han tenido un mayor peso en la teoría que en la praxis. En particular, se revisan experiencias de regeneración urbana de la década de 1970 en dos barrios históricos centrales y populares; ejercicios de planeación urbana participativa en el centro histórico, realizados entre 1998 y 2000, e intervenciones recientes (de la década de 2010) en barrios autoconstruidos consolidados en periferias urbanas. Este trabajo recoge los resultados de diversas investigaciones sobre las políticas urbanas y habitacionales en áreas urbanas centrales y periféricas de la capital mexicana realizadas en los últimos años.

\section{Un concepto polisémico, pero no neutro}

Regeneración es un concepto que, como otros en urbanismo (hábitat, rehabilitación)², es tomado de las ciencias naturales. En biología, este concepto alude a la recreación de un tejido vivo, perdido o lesionado, o a la reconstitución de un organismo o sistema vivo a su estado inicial. En urbanismo, la regeneración concierne a la restitución de las características de un tejido urbano perdidas por la degradación física (a menudo equiparada

2 Rehabilitación, en materia de derecho, significa reponer una posesión o reintegrar créditos, honra o cargos. Sin embargo, su significado médico es símil de la práctica urbanística: métodos para recuperar una actividad o función perdida o disminuida por enfermedad o traumatismo (Real Academia Española [RAE], 2020). 
a degradación social), la pérdida de funciones urbanas, la desvalorización de rentas, el declive de población y de actividades económicas (Centro Operacional de Poblamiento y Vivienda [COPEVI], 1974; Couch, Fraser y Percy, 2003; Smith, 2012).

El concepto también alude a una dimensión moral. Diversas autoridades civiles han usado este concepto para confrontar lo que consideran como conductas antisociales, descarriladas y/o el deterioro moral de la gente (Smith, 2012).

El concepto surgió en la década de 1960, frente a la renovación urbana, que hacía tabula rasa a los barrios existentes declarados decadentes, para sustituirlos por nuevos edificios $e$ infraestructuras. En efecto, la "renovación urbana" (otro concepto polisémico con contenidos morales) ${ }^{3}$ se distingue claramente de la regeneración urbana, porque la primera consiste en la destrucción y reconstrucción completa de los barrios deteriorados, mientras que la segunda confronta el deterioro urbano sin destruir el tejido físico y social. Jacobs (1967) usaba el concepto regeneración en oposición a los proyectos de renovación urbana que amenazaban con desaparecer los barrios habitados de su ciudad, supuestamente "deteriorados". Para Jacobs, el deterioro urbano

3 Klemek (2011) sostiene que, desde su origen, en Estados Unidos, la renovación urbana se asocia a una doctrina conservadora que pretende reformar de raíz los barrios deteriorados, a través de su erradicación, por ser habitados por pobres con conductas antisociales y delincuenciales. no tenía nada de natural; la riqueza y vitalidad urbana radicaban en una gran diversidad social, económica, política y cultural de los barrios y las ciudades y la transformación y regeneración urbana sólo se podrían realizar con la más amplia participación de la gente, que da vida a los barrios a través de su práctica cotidiana y de la (re)producción de sus relaciones sociales de proximidad.

En la Ciudad de México, en una época donde prevalecían las teorías de la marginalidad y la dependencia, COPEVI realizó entre 1972 y 1974 un "Estudio para la regeneración urbana" (COPEVI, 1974) de la capital mexicana. COPEVI diferenciaba la precariedad de los barrios nuevos, autoconstruidos en las periferias urbanas, del deterioro de los barrios antiguos, que consistía en el menoscabo de las condiciones originales de las estructuras habitacionales y urbanas, la vida pública, el medio ambiente y/o las funciones urbanas. COPEVI claramente diferenciaba la regeneración urbana de otros conceptos que ya entonces eran confundidos como sinónimos: renovación urbana (destrucción de lo existente y sustitución con nueva construcción de espacios habitables), remodelación urbana (reordenación física de la imagen urbana) y rehabilitación urbana (volver a habilitar barrios para que sigan funcionando). Estos eran conceptos centrados en la dimensión económica y física del deterioro urbano; en cambio, la regeneración urbana era un concepto amplio, que consistía en poner en marcha un proceso integral que, desde 
diversos frentes, confrontaría las múltiples causas que originaban el deterioro urbano ${ }^{4}$. Las estrategias de regeneración urbana, por definición, eran holísticas; tenían en cuenta las dialécticas relaciones centro periferia, incluían la participación ciudadana, garantizaban un aprovechamiento y redistribución justa de los recursos urbanos entre propietarios, inquilinos ${ }^{5}$ y usuarios, y evitaban las zonificaciones rígidas y homogéneas que contradicen la naturaleza dinámica y heterogénea de la ciudad.

En la literatura más reciente, la regeneración urbana aparece con frecuencia en aportaciones anglosajonas. Para Smith (2012), el concepto regeneración urbana abarca una diversidad de acciones destinadas a revertir el declive urbano, atendiendo las condiciones socioeconómicas y medioambientales para recuperar las condiciones que un barrio tuvo alguna vez. Couch et al. (2003) argumentan que la vigencia de la regeneración urbana se debe a los drásticos cambios padecidos por las ciudades británicas en el último tercio del siglo XX: dejaron de ser centros de producción industrial y se transformaron en centros de servicios y consumo, padeciendo un proceso

$4 \quad$ Estas mismas diferencias conceptuales son reconocidas por Matesanz (2016) y por un "Glosario de desarrollo espacial" de la Comunidad Europea ("Spatial development glossary", 2007).

5 En un momento en que la vivienda en alquiler era mayoritaria en México y estaban vigentes los decretos de "congelamiento" de alquileres. de descentralización y suburbanización que culminó en el abandono de los barrios centrales, el deterioro del medio ambiente, el desempleo y una aguda privación social. La regeneración urbana quiere confrontar estos problemas volviendo a utilizar los edificios abandonados y el suelo vacante y creando nuevas formas de empleo. Estos autores estudian las políticas de regeneración urbana en Inglaterra y Europa, en el marco de la competitividad económica entre ciudades, las asociaciones público-privadas y el aprovechamiento de eventos mediáticos para la transformación de selectas partes de la ciudad. Aquí, el concepto regeneración urbana es utilizado de modo aséptico y al margen de cualquier disputa y conflicto social. Justo por ello, los estudiosos de la gentrificación (Lees, Slater y Wyly, 2008; Sorando y Ardura, 2016) critican el uso de un léxico supuestamente neutro, despolitizado y a veces hasta filantrópico, como regeneración, renovación o renacimiento urbano, para esconder el verdadero interés tras esas políticas urbanas neoliberales: el lucro del capital con efectos sociales devastadores. Tatcher, por ejemplo, usó la "regeneración urbana" como medicina para la "degeneración social" y el declive económico (Lees et al., 2008, p. xix).

La polisemia y la disputa por los contenidos de los conceptos prevalece en nuestros días. Así, por ejemplo, Lees et al. (2008) muestran cómo el concepto gentrificación es utilizado como sinónimo de génesis y/o de genocidio urbano y 
social. Mientras que Rojas, Rodríguez y Wegelin (2004), desde la ideología neoliberal del Banco Interamericano de Desarrollo, sostienen que "recuperación urbana" es el mejor concepto para referirse al conjunto de acciones públicas que pretenden mejorar social y económicamente una zona urbana que padece deterioro social, físico, económico y presenta subutilización de sus "activos" (edificios, infraestructura, espacios urbanos).

Matesanz (2016), plantea la evolución del concepto regeneración urbanaen Europa, a partir de dos corrientes de pensamiento diferentes, en una trayectoria histórica que evoluciona a partir de teorías marxistas y paradójicamente culmina con una praxis neoliberal. Una corriente, que llama mediterránea, se ancla en la concepción lefebvriana del derecho a la ciudad (Lefebvre, 1991), la autogestión y las experiencias del "recupero" del patrimonio urbano en Italia, que dieron paso a una concepción integrada e integradora de mejoramiento de los tejidos urbanos existentes en beneficio de los residentes. Mientras que la otra corriente anglosajona (Estados Unidos y Reino Unido), heredera de la renovación urbana tipo tabula rasa, pretende combatir la pobreza y la marginación en barrios centrales desfavorecidos a través de la erradicación de la infravivienda. Es una corriente abiertamente pro capitalista -dice Matesanz- que promueve las inversiones privadas ante la falta de recursos públicos, para que los barrios degradados alcancen su desarrollo económico y social a cualquier costo, incluso el del desplazamiento de la población desfavorecida que originalmente se quería beneficiar.

Con la consolidación del neoliberalismo y en un momento en que la ciudad se concebía como el motor de la economía y la planeación urbana se tornó en planeación estratégica (es decir, fragmentaria), la corriente mediterránea se fue erosionando y la corriente anglosajona se convirtió en el mainstream en Europa. Un claro ejemplo de ello ocurrió en España (Matesanz, 2016), país que en las décadas de 1970 y 1980 abrazó la corriente urbanística mediterránea bajo el concepto rehabilitación urbana. Sin embargo, con el ingreso a la Comunidad Europea y gracias a los grandes flujos financieros internacionales que llegaron a este país, asociados a su modelo económico y de mercado inmobiliario de construcción nueva, España terminó por adoptar, de manera muy residual, ${ }^{6}$ el modelo anglosajón de regeneración urbana integrada, así apellidada por la Comunidad Europea.

Coincidiendo con este análisis, Castrillo, Jiménez, Santos y Lalana (2014) y Bonet i Martí (2012) contrastan cómo las experiencias de rehabilitación urbana en España, de las décadas

6 Residual, porque las políticas se dirigieron a la construcción nueva en escala colosal. Matesanz (2016) incluso reconoce que en estos casos se privilegió la renovación urbana (tabula rasa) por ser más lucrativa que la regeneración urbana integrada. 
de 1970 y 1980, contenían ricas expresiones de auténtica participación ciudadana; mientras que en las experiencias más recientes de regeneración urbana integrada, cofinanciadas por la Comunidad Europea, la participación ciudadana es una "coartada" que legitima decisiones tomadas por las autoridades y los negocios inmobiliarios (como en Malasaña, Madrid, donde la sociedad civil que participa es un Consejo de inversionistas). Así, estos autores claramente diferencian la participación ciudadana por irrupción, de la "participación social" por invitación.

Siguiendo con la polisemia del concepto, en un interesante informe sobre regeneración urbana integrada en los países que integran la Comunidad Europea, los colegas españoles que coordinaron la investigación (Álvarez Mora y Roch Peña, 2010) dan cuenta que la regeneración urbana no es sino un conjunto de prácticas muy disímbolas, que abarcan o excluyen la vivienda, atienden unos barrios desfavorecidos y promueven en otros la creación de barrios exclusivos y la gentrificación. Asimismo, los territorios objeto de regeneración son muy diversos: centros históricos, brownfields, barrios periféricos, conjuntos de vivienda social, etcétera. Además, no hay nada de visión de conjunto, ni de la ciudad como totalidad (cosa que quería acentuar el apellido del concepto). Curiosamente, este informe destaca que España era el país donde había más viviendas nuevas construidas, más viviendas por habitantes y más población económicamente activa ocupada en el sector de la construcción. Se trata de indicadores que muy poco tienen que ver con la regeneración urbana (motivo del informe) en España, pero que claramente reflejan el modelo de construcción nueva y urbanización difusa en escala colosal desarrollado con efectos perversos para la gente y el territorio: 3.4 millones de viviendas vacías, paisajes devastados, cientos de miles de desahuciados, colosales artefactos a medio construir convertidos en "ruinas modernas", etcétera.

Por otro lado, en América Latina, varios colegas y marcos jurídicos de las últimas décadas conciben a la renovación urbana de otra forma, no como tabula rasa. En Colombia, la Ley Nacional de Ordenamiento Territorial de 1997 equipara el mejoramiento urbano integral con la renovación urbana. En Chile, la ley N 18595 (1987) crea la figura de "zonas de renovación urbana", definidas como aquellas áreas delimitadas por la municipalidad que requieren de mejora, rehabilitación, remodelación o renovación, que serán objeto de beneficios tributarios. Mientras que Carrión (2005) habla de la "renovación" de los centros históricos con el objeto de preservar su legado histórico, no para reconstruir su pasado sino para encarar su futuro. Curiosamente, el reciente libro "Regeneración y revitalización urbana en las Américas" (Carrión y Hanley, 2003) no define esos dos conceptos y cuando habla expresamente de renovación urbana, tampoco la define. Tal vez son conceptos intercambiables para sus autores. 


\section{Una praxis similar con distintos nombres}

En Alemania el concepto Stadterneuerung (renovación urbana) se usa indistintamente para hablar, tanto de la nueva construcción, previa destrucción de edificios y barrios, como de la mejora y preservación de edificios y barrios existentes (Schubert, 1998). En la década de 1980 se introdujo una nueva forma de intervenir en los barrios existentes: la behutsame Stadterneuerung (renovación urbana cuidadosa). Se trata de una doctrina urbanística que tiene como principios fundamentales: la participación de residentes en la toma de decisiones sobre el futuro del barrio; el fomento de la autoayuda en la construcción y la rehabilitación edilicia; los criterios ecologistas en el diseño urbano, y la preservación del tejido urbano y social. Entre 1984 y 1987, Kreuzberg, un barrio berlinés densamente habitado y deteriorado, fue sustancialmente mejorado: la población alemana y los inmigrantes turcos permanecieron en el barrio en viviendas mejoradas en régimen de alquiler moderado, se preservaron los edificios existentes y se introdujeron nuevos sin romper la escala del barrio, se modernizaron los servicios y la infraestructura urbana y los centros de manzana densamente construidos fueron des-densificados para crear áreas verdes y equipamientos de barrio ("Schritt für Schritt", 1990; Segado-Vázquez y EspinosaMuñoz, 2015). Para la década del 2010, con la consolidación del neoliberalismo, los colegas alemanes hablan de la gentrificación de sus ciudades y de la pérdida del adjetivo (cuidadosa) que otorgó contenidos sociales a la renovación urbana (Beaufils, 2010; Dörfler, 2010).

En Francia, la renovación urbana -muy difundida entre las décadas de 1950 y 1970claramente significaba la destrucción del tejido urbano existente para la construcción de nuevas edificaciones y estructuras urbanas (Centre de documentation de l'urbanisme [CDU], 1995) ${ }^{7}$. En la década de 1970 se introdujeron las Operaciones Programadas de Mejoramiento del Hábitat, instrumento urbanístico que promueve el mantenimiento de los residentes, la vivienda en alquiler y la participación de los propietarios e inversionistas en la mejora y rehabilitación del barrio, sea viejo o nuevo, a través del otorgamiento de subvenciones públicas diversas y la concentración de acciones de mejoramiento de equipamientos y servicios en los barrios. Se trata de la rehabilitación urbana y del progresivo mejoramiento del hábitat (viviendas, edificios y barrios) que aprovecha las estructuras existentes en lugar de destruirlas para construir todo de nuevo (Duport, 1989). La gestión de la rehabilitación urbana, entre las décadas de 1960 y 1990, era desarrollada por equipos

$7 \quad$ Esto cambió con la Agencia Nacional para la Renovación Urbana, creada en 2003, por una ley que en la definición de renovación urbana incluye muy diversas formas de intervención física (demoliciones, reconstrucciones, mejoramientos, rehabilitación). 
técnicos especializados, independientes de las autoridades, quienes realizaban los estudios, canalizaban los subsidios y el financiamiento público, negociando con los propietarios y estableciendo contacto con los residentes.

En España, Iglesias, Martí-Costa, Subirats y Tomás (2011) señalan que en la década de 1990 la reconfiguración de las políticas urbanas puso el acento en un gerencialismo proclive a los negocios privados, las infraestructuras culturales y educativas, el desarrollo económico y la regeneración de los cascos antiguos con fondos europeos. Las políticas de regeneración y rehabilitación urbana en escala de barrios pusieron el acento en la integralidad y multidimensionalidad de los procesos y los problemas urbanos, y se propusieron realizar intervenciones holísticas intentando articular una red de actores diversos en los territorios urbanos. Resulta interesante que Borja (1995), en una de las publicaciones que colocan a Barcelona como ejemplo internacional de transformación urbana, habla de cuatro conceptos que no define, tal vez asumiendo que son sinónimos: renovación urbana, reforma interior, rehabilitación y recualificación urbana.

Otro caso de regeneración urbana, que se convirtió en hito en Europa y América Latina, fue la recuperación del centro histórico de Bolonia, realizada en la década de 1970: la población residente no fue desplazada; se mejoraron la vivienda y los servicios del barrio; se mantuvo la mezcla de usos del suelo, de población diversa y de actividades; y los estudios tipológicos (innovadores en esa época) fueron la base para definir los usos y las acciones físicas más apropiadas para la preservación del patrimonio edilicio (restauraciones, rehabilitaciones, demoliciones puntuales).

Hay dos constantes en este conjunto de prácticas realizadas por gobiernos eurocomunistas en Italia, "socialistas" en España, y socialdemócratas en Francia y Alemania: una en que la intervención en los tejidos urbanos claramente se propone la permanencia de los residentes; otra, en que el énfasis está puesto en la participación ciudadana en la toma de decisiones. Evidentemente, estas formas de intervención han mutado gradualmente desde la década de 1990 con la consolidación del neoliberalismo.

Por otra parte, en América Latina hay algunas experiencias que podemos catalogar como de regeneración urbana, como las intervenciones después de los sismos de 1985 y 1987 en los centros históricos de Ciudad de México y Quito, respectivamente (Delgadillo, 2011). Sin embargo, en materia de centros históricos no es común el uso de tal concepto: en las décadas de 1970 y 1980 se hablaba de restauración, recuperación y rehabilitación urbana; posteriormente esos conceptos coexisten con el de recualificación urbana, planes integrales de desarrollo, y los actuales planes de manejo y gestión. 
En materia de retorno al centro y a la ciudad existente, más bien encontramos el acento en políticas sectoriales de vivienda (con subsidios públicos), flexibilización de normas urbanas e incentivos fiscales y administrativos para la densificación edilicia y los negocios inmobiliarios (Delgadillo, 2016). Asimismo, los programas de mejoramiento de los barrios autoconstruidos por población de bajos ingresos, que desde fines de la década de 1980 se realizan en Suramérica, han incorporado parte de los contenidos de la regeneración urbana: atención holística de los problemas de los barrios (carentes de servicios, infraestructuras y espacios comunitarios) y participación de los residentes en la mejora y en la toma de decisiones sobre el futuro de sus barrios.

\section{Experiencias de regeneración urbana en la Ciudad de México}

En la capital mexicana, la regeneración urbana ha sido más un deseo de visionarios urbanistas (limitada a la realización de ejercicios de planificación urbana participativa) que una práctica concreta. Curiosamente, se trata de un concepto que vuelve a ser utilizado en las políticas urbanas nacionales y locales a partir de 2019.

A fines de la década de 1970 y principios de la de 1980, los residentes organizados de dos barrios históricos centrales y populares -que fueran arrabales durante la coloniaGuerrero (Cooperativa de Vivienda y Servicios Habitacionales) y Tepito, establecieron un convenio con la Escuela Nacional de Arquitectura Autogobierno, de la Universidad Nacional Autónoma de México, para desarrollar programas de mejoramiento de sus barrios y confrontar los problemas de los derrumbes y las "soluciones" de tabula rasa que promovían las autoridades. Universitarios y vecinos elaboraron diagnósticos integrales que incluyeron estudios de tipología habitacional, propiedad del suelo y espacios públicos; de estos se desprendieron proyectos habitacionales (reconstrucción, rehabilitación, mejoramiento) y de espacios urbanos (parques, plazas, pasos peatonales); así como estrategias de actuación en escala de predio que preservaban la mezcla de vivienda, talleres, servicios y comercios, y la tipología edilicia de baja altura. Estas propuestas que comenzarían a aplicarse gradualmente fueron detenidas por los sismos de 1985 y los posteriores programas de reconstrucción habitacional (Connolly, Duhau y Coulomb, 1991; Suárez Pareyón, 1978).

Dos décadas después, durante el primer gobierno democráticamente electo en la historia de la Ciudad de México (1997-2000), se realizaron experiencias de regeneración urbana en el centro histórico de la ciudad, que se limitaron a ejercicios de planeación participativa. El Fideicomiso Centro Histórico realizó un Plan estratégico para la regeneración y 
el desarrollo integral de ese sitio, que pretendía construir una nueva centralidad socialmente inclusiva, aprovechar la riqueza patrimonial y la heterogeneidad socioeconómica, mantener la función habitacional y la población residente, y mejorar la calidad de vida de la población que habita, trabaja o visita este territorio. Por su parte, el Centro de la Vivienda y Estudios Urbanos (CENVI), desarrolló un programa de planeación urbana que sirvió de base para el Programa Parcial de Desarrollo Urbano del Centro Histórico, que fija normas para los usos del suelo, las intensidades constructivas y la preservación de los inmuebles catalogados como patrimonio histórico; este fue aprobado con carácter de ley por la Asamblea Legislativa local. Sin embargo, ninguno de los planes efectuó los proyectos ni las acciones planteadas para confrontar el deterioro urbano.

Curiosamente, a partir de 2019, los gobiernos federal y local, ambos del partido Movimiento de Regeneración Nacional que arrasó las elecciones de julio de 2018 y que se asume de "izquierda", han anunciado políticas de regeneración urbana, tal vez más por asociarlas al nombre de este partido político que por considerar los contenidos del concepto. La Secretaría de Desarrollo Agrario, Territorial y Urbano del gobierno federal promueve con el Instituto Nacional del Fondo de Vivienda para los Trabajadores $^{8}$, un programa que pretende usar

$8 \quad$ INFONAVIT es un fondo social creado en 1972 con el 5\% del salario de los trabajadores que laboran en el sector privado.
171 mil viviendas abandonadas, que son parte de los cinco millones de viviendas vacías que entre 2000 y 2012 produjo la financiarizada política habitacional de los gobiernos neoliberales en periferias urbanas distantes. Aquí se habla de usar "esquemas de regeneración urbana" para hacer habitables barrios con viviendas de dimensiones y calidad miserables, en entornos sin equipamientos ni servicios y alejados de las ciudades. Una pregunta perogrullesca sería ise puede regenerar lo que nunca se ha generado?

Por su parte, la Secretaría de Desarrollo Urbano y Vivienda del gobierno de la Ciudad de México, anunció su "Programa Especial de Regeneración Urbana y Vivienda Incluyente". Con un discurso que dice que la "ciudadanía es el eje central" del gobierno, este programa define acciones en doce corredores urbanos en selectas áreas centrales. Aquí, la regeneración aparece como la suma de acciones de vivienda, comercios, espacio público, infraestructura, movilidad y centros sociales. En estos selectos corredores se destinaría un 30\% de la vivienda producida a "vivienda asequible" para las familias que residen en esos predios, un 40\% deberá venderse en 9,000 Unidades de Medida $^{9}$ (en marzo de 2020 son 781,920 pesos

Ese año se crearon otros dos fondos sociales para la vivienda de los trabajadores del Estado y del sistema militar.

9 Indicador económico introducido en México en enero de 2016, en sustitución del indicador Salario Mínimo diario, para calcular el pago de obligaciones fiscales, multas diversas y el precio de la vivienda. 
mexicanos o 32,580 dólares) y un 20\% con un precio máximo de 1.15 millones de pesos. Asimismo, por decreto, el precio por metro cuadrado no debería rebasar las 188 unidades de medida (16.3 mil pesos). Bajo este esquema se producirían entre 7,500 y 10,000 viviendas asequibles. El programa no explicita cómo es que la vivienda asequible llegará a la gente que allí habita: ¿comodato, cesión de uso?, ipropietarios con créditos bancarios o con hipotecas y subsidios públicos?, ¿inquilinos en régimen de alquiler moderado por equis temporalidad? La autoridad local sostiene que la política de desarrollo urbano ha cambiado: de excluyente a una incluyente. Sin embargo, en una ciudad con 23 años de gobierno de "izquierda", es muy difícil creer en las buenas intenciones en turno, pues varios instrumentos urbanísticos que se institucionalizaron para producir vivienda social (como la llamada Norma 26) o distribuir equitativamente los costos y beneficios del desarrollo urbano (sistema de transferencia de potencialidad del desarrollo urbano) terminaron por facilitar los lucrativos negocios de unos cuantos (Delgadillo, 2016).

\section{Regeneración urbana y mejoramiento barrial}

El Programa Comunitario de Mejoramiento Barrial (PCMB) fue introducido en la capital mexicana en 2007 para atender las carencias de los barrios auto producidos con los esfuerzos de sus habitantes en las últimas décadas, teniendo muchos de ellos 50 o más años. Este programa ya había atendido a 1,927 barrios, para 2017. El programa reconoce la capacidad de la gente para la autoconstrucción de su vivienda, barrio y ciudad, y que los barrios autoconstruidos son un hecho irreversible, pero presentan carencia de servicios, equipamientos urbanos, infraestructura y espacios públicos. De manera proporcional a su éxito internacional (obtuvo reconocimientos del Deutsche Bank y de ONU Hábitat), los objetivos, metas y presupuesto de este programa fueron disminuidos por el gobierno central, debido a disputas al interior del gobierno. A pesar de que la mayor parte de esta política focalizada se limita a acciones de imagen urbana (pintar fachadas) y muy puntuales (un inmueble), y que a menudo la participación ciudadana se reduce al cumplimiento de un requisito, en este texto analizamos un par de casos muy cercanos al espíritu de la regeneración urbana: colectivos sociales organizados con apoyo de asesores técnicos sin fines de lucro (universidades, organismos no gubernamentales) que, a través de procesos participativos, logran capturar algunos recursos públicos para confrontar deterioro, precariedades y mejorar sus barrios existentes.

En la Sierra de Santa Catarina de Iztapalapa destacamos cuatro experiencias. Iztapalapa es una Alcaldía donde reside la quinta parte de la población de la capital mexicana (1.9 
millones de habitantes), que se caracteriza por la precariedad, la pobreza y la carencia de servicios y equipamientos urbanos:

- Miravalle: Comunidad muy bien organizada desde las luchas por la regularización de sus barrios en las décadas 1970 y 1980. Tres veces consecutivas ganó recursos del PCMB, para crear espacios de uso colectivo: la primera para un Kiosco multiusos; la segunda para una cubierta para una plaza (Figura 1) que posibilita diversas actividades sociales, culturales y políticas; y la tercera para un centro cultural, que sirve de escuela taller para jóvenes del barrio.

- Bellavista: Además de edificar un comedor comunitario, el colectivo social amplió sus actividades hacia la agricultura urbana y se apropió de un camellón público para producir hortalizas al servicio del comedor.

- Xalpa: Esta comunidad concursó sin éxito por recursos del PCMB para edificar su centro social. Sin embargo, en una gira de la autoridad local en 2012, consiguieron presentar su proyecto y la autoridad apoyó su realización. En años posteriores han ganado recursos del PCMB para construir plazas, jardines y áreas deportivas en torno a su centro social.
- Desarrollo Urbano Quetzálcoatl es un conjunto de barrios que surgieron en la década de 1970 para alojar a población de bajos ingresos desalojada del centro de la ciudad por la construcción de vialidades y proyectos urbanos. El espacio ocupado por el Foro Cultural Quetzalpili era un terreno anegado, que en 1997 fue cercado por las autoridades para destinarlo a espacio público pero terminó convirtiéndose en basurero. La lucha de las vecinas, ahora adultas mayores, por recuperar este baldío y destinarlo a un uso social se remonta al año 2000. El colectivo ganó en cuatro ocasiones recursos del programa para edificar su Foro en fases, contando este con juegos infantiles, canchas deportivas, auditorio abierto -cubierto con una membrana de lona- (Figura 2), escenario, aulas de danza y salas de diversos usos.

En otra zona de barrancas de la ciudad, destacan los barrios que integran un área urbana llamada "La Mexicana". Aquí, los colectivos sociales, apoyados por una universidad privada, ganaron recursos del PCMB para construir escaleras para subir y bajar las empinadas cuestas, para crear plazas con juegos infantiles (Figura 3) y para rehabilitar una parte de la ribera del río Tacubaya, donde el colectivo -por iniciativa propia- comenzó a producir hortalizas en invernaderos. 
En un barrio central, en Iztacalco, hacia el año 2000, vecinos del barrio preocupados por la inseguridad y delincuencia de la zona, y cansados de la ausencia de seguridad pública, decidieron tomar un terreno baldío, que era un basurero, para construir un proyecto comunitario que congregara a los jóvenes y vecinos. En el 2010 y los años subsecuentes el colectivo obtuvo recursos del programa para construir en fases la Casa de la Cultura Las Jarillas. Este colectivo ha continuado impulsando acciones de mejora en el barrio: introducción de sistemas de captación de agua y paneles solares tanto en la Casa de Cultura como en viviendas del barrio para abaratar los costos de agua y luz (Figura 4).

Resulta interesante que sean mujeres adultas mayores quienes en las periferias urbanas comandan esos procesos organizativos, mientras que en las áreas urbanas centrales los actores son más jóvenes, están articulados con otros colectivos sociales de la ciudad y tienen un mayor capital político que les permite negociar en mejores condiciones apoyos puntuales en favor de sus comunidades.

Construir estos espacios comunitarios ha costado años de trabajo, pero el objetivo es utilizarlos en beneficio de las comunidades locales. Todos estos centros comunitarios funcionan sin presupuesto público. Con recursos propios se imparten cursos y talleres voluntarios que a menudo cobran cuotas simbólicas para reponer algún material.
Sin embargo, han surgido discrepancias y conflictos entre colectivos y autoridades. Para los colectivos esas obras existen gracias a su capacidad organizativa y de movilización; mientras que, para las autoridades de las Alcaldías, esos centros comunitarios fueron construidos con recursos públicos (del gobierno central) y en predios de propiedad pública, por lo que corresponde a las autoridades locales hacerse cargo de su funcionamiento. Así, por ejemplo, el centro comunitario de Xalpa es administrado por las autoridades locales y en algunos períodos de gobierno (de 3 años) lo han llegado a cerrar en sábados y domingos, justo cuando la gente más necesita de este espacio debido a que niños y jóvenes no tienen escuela. Asimismo, el mismo día que se inauguró el Foro Cultural Quetzalpili, éste fue utilizado por la Delegada (alcaldesa) para transmitir en pantallas grandes una actividad política suya, mientras que con el sismo de septiembre de 2017 el Foro se utilizó durante meses como escuela provisional. Así, varios colectivos demandan que esos centros sociales funcionen con recursos públicos pero que sean administrados por ellos, debiendo explorar formas y figuras jurídicas que les permitan controlar sus espacios colectivos frente a los vaivenes de los políticos y las políticas. Así, la regeneración urbana no termina con la conquista de obras físicas; éstas apenas son un medio para posibilitar el desarrollo social en su más amplia expresión. 
FIGURAS 1 Y 2. PLAZA CUBIERTA, MIRAVALLE, Y FORO QUETZALPILI, DESARROLLO URBANO QUETZALCÓATL.
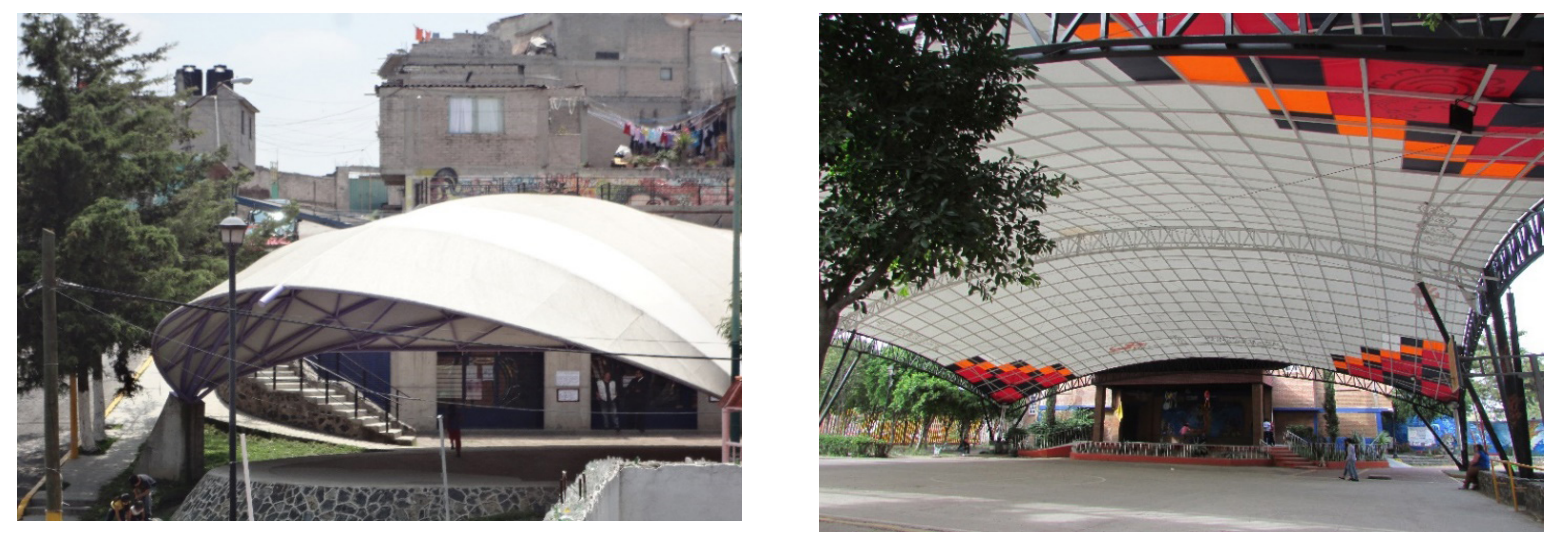

Fuente: Autor, 2019.

FIGURAS 3 Y 4. ÁREA DE JUEGOS INFANTILES, LA MEXICANA, Y SISTEMAS DE CAPTACIÓN DE AGUA, IZTACALCO.
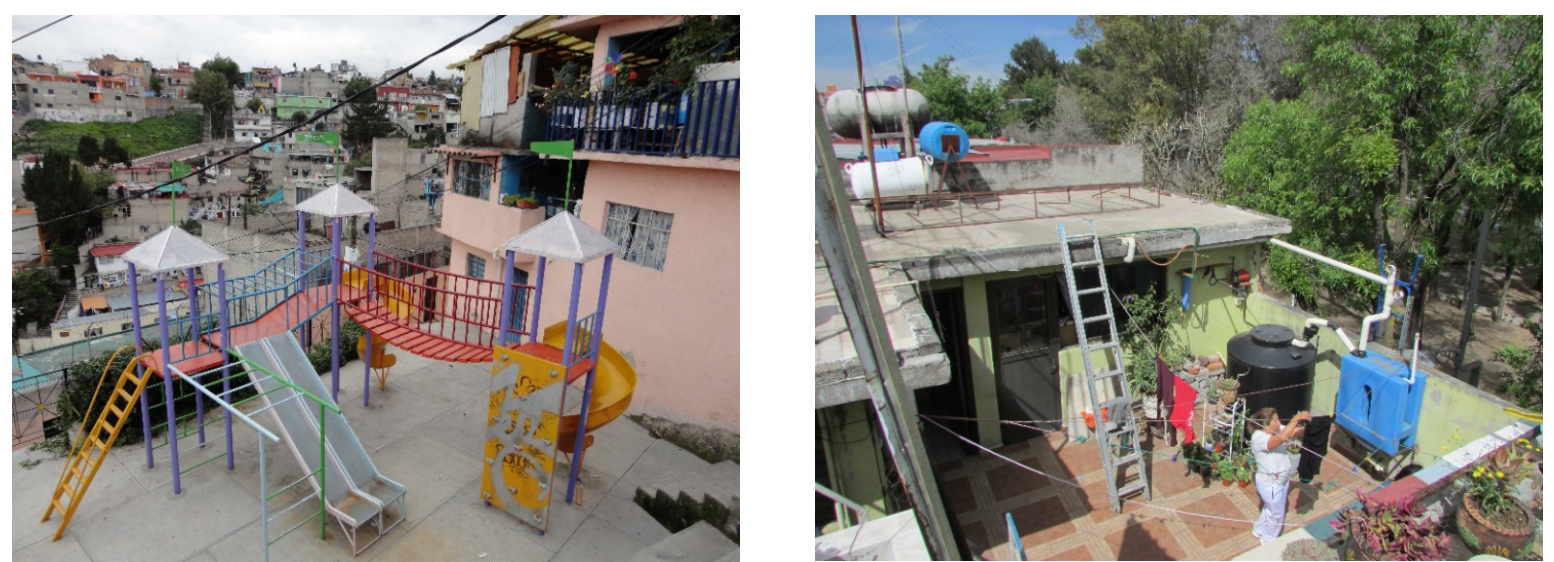

Fuente: Autor, 2019 


\section{Conclusiones}

Los conceptos no son neutros ni despolitizados, y su uso y apropiación responde a visiones e ideologías sobre el mundo y el desarrollo, y a posturas políticas. Así, la regeneración urbana era asociada por COPEVI y Jane Jacobs con un urbanismo democrático, participativoy construido desde abajo. Sin embargo, en el Reino Unido del siglo XXI, ese mismo concepto es utilizado como un instrumento para la competencia entre ciudades neoliberales. Entonces tiene sentido preguntarnos: ¿Regeneración urbana para quiénes y según quiénes?

Los principios de intervención urbana que guiaron la behutsame Stadterneuerung alemana y la rehabilitation urbana francesa son casi los mismos que asociamos a la regeneración urbana: inclusión y participación social, atención multidimensional a los problemas urbanos y evitación del despilfarro urbano (a través de la mantención y mejora de las estructuras edilicias y los tejidos sociales, así como de la mezcla de usos del suelo, de actividades económicas y de grupos de población). Así, la visión participativa de la planeación y la gestión urbana trasciende los conceptos. En este mismo sentido, destacamos que en la época del Estado Benefactor hubo programas de regeneración urbana que mejoraron las condiciones de los barrios y de la gente; mientras que en el siglo XXI hay programas de regeneración urbana que con discursos técnicos legitiman y promueven los negocios inmobiliarios y solo a veces, de manera residual y focalizada, atienden viejas demandas de algunos grupos sociales organizados.

En este mismo sentido, señalamos que las experiencias de regeneración urbana de la década de 1970 en Europa y América Latina incluían formas auténticas de participación ciudadana (autogestión, demandaría Lefebvre, 1991) derivadas de demandas e irrupciones, frente a una actual "participación social" acartonada e institucionalizada que se realiza para cumplir requisitos de organismos internacionales (Comunidad Europea) y gobiernos de "izquierda". En estos casos se trata de legitimar decisiones ya tomadas y de negocios privados. Asimismo, la participación ciudadana latinoamericana, derivada de formas de supervivencia y de una constante demanda por servicios y equipamientos urbanos, contrasta con una participación ciudadana europea a menudo calificada de "inusual" y recientemente de "innovación social” (Michelin, 2019).

La Ciudad de México presenta un enorme rezago en materia de políticas, instituciones e instrumentos para enfrentar los desafíos que representa el deterioro urbano y habitacional en escala de barrios centrales y periféricos. Aquí no hay fondos específicos, ni líneas de financiamiento diversas para la rehabilitación urbana. Tampoco hay nada parecido a una gestión del desarrollo integral del barrio que 
incorpore a los propietarios y residentes y escuche sus necesidades.

Las experiencias de mejoramiento de barrios populares, aquí analizadas y consideradas como regeneración urbana, han sido procesos muy largos. Aquí, los colectivos sociales tienen que continuar haciendo esfuerzos propios para que sus centros sociales funcionen en beneficio de la gente y tienen que disputar con las autoridades el derecho a gestionarlos. En síntesis, la regeneración urbana en México ha sido más una aspiración de actores que defienden un urbanismo participativo y tal vez una conquista, puntual y limitada, de algunos grupos organizados.

\section{Referencias bibliográficas}

Álvarez Mora, A. y Roch Peña, F. (Dirs). (2010). Regeneración urbana integrada en Europa. Documento de sintesis. Valladolid: Universidad de Valladolid. Recuperado de

https://www.fomento.gob.es/nr/rdonlyres/ 94c72ebl-d0e7-428a-9039-a73588c47866/95964/ urban regene spanish.pdf

Beaufils, C. (2010). Gentrifizierung in Europas Metropolen. Das Phänomen der Gentrifizierung in Berlin im Vergleich zu London. München: GRIN.

Bonet i Martí, J. (2012). El territorio como espacio de radicalización democrática. Una aproximación crítica a los procesos de participación ciudadana en las políticas urbanas de Madrid y Barcelona. Athenea Digital, 12(1), 15-28.

https://doi.org/10.5565/rev/athenead/v12n1.914
Borja, J. (Ed.). (1995). Barcelona, un modelo de transformación urbana 1980-1995. Quito: PGU.

Carrión, F. (2005). El centro histórico como proyecto y objeto de deseo. Eure, 31( 93), 89-100. https://doi.org/10.4067/S0250-71612005009300006

Carrión, F. y Hanley. L. (Eds.). (2003). Regeneración y revitalización urbana en las Américas: hacia un Estado estable. Quito: FLACSO Ecuador.

Castrillo, M., Jiménez, M., Santos, L., y Lalana, J. (2014). "Derecho a la ciudad" vs "participación ciudadana". La rehabilitación urbana y el rol de los habitantes desde la perspectiva de los vecinos militantes de los barrios de Valladolid (España), 1970-2013. En VIII Congresso português de sociología: 40 anos de democracia(s): progressos, contradições e prospetivas. Recuperado de: https://associacaoportuguesasociologia.pt/viii congresso/VIII ACTAS/VIII COM0292.pdf

Centre de documentation de l'urbanisme. (1995). La réhabilitation en France, outils et procédures. Paris: ANAH.

Connolly, P., Duhau, E., y Coulomb, R. (1991). Cambiar de casa pero no de barrio. Estudios sobre la reconstrucción en la Ciudad de México. México: CENVI, UAM Azcapotzalco.

Couch, C., Fraser, Ch., y Percy, S. (Eds.). (2003). Urban regeneration in Europe. Oxford: Blakwell.

Centro Operacional de Poblamiento y Vivienda. (1974). Documentos sobre regeneración urbana. Dinámica habitacional (México), (supl. A2), 71.

Delgadillo, V. (2011). Patrimonio histórico y tugurios. Las políticas de rehabilitación de vivienda y de recuperación de los centros históricos de Ciudad de México, Quito y Buenos Aires. México: UACM. 
Delgadillo, V. (2016). Ciudad de México, quince años de desarrollo urbano intensivo: la gentrificación percibida. Revista INVI, 31(88), 101-129. http://revistainvi.uchile.cl/index.php/INVI/article/ view/1088

Dörfler, T. (2010). Gentrification in Prenzlauerberg? Milieuwandel eines Berliner Sozilraums seit 1989. Bielefeld: Transcript.

Duport, J. P. (Dir.). (1989). 40 ans de Réhabilitation de thabitat en France. Paris: Economica.

Iglesias, M., Martí-Costa, M., Subirats, J., y Tomás, M. (Eds.). (2011). Politicas urbanas en España. Grandes ciudades, actores y gobiernos locales. Barcelona: Icaria.

Jacobs, J. (1967). Muerte y vida de las grandes ciudades. Madrid: Península.

Klemek, C. (2011). The transatlantic collapse of urban renewal. Postwar urbanism from New York to Berlin. Chicago: The Chicago University Press.

Lees, L., Slater, T., y Wyly, E. (2008). Gentrification. New York: Routledge.

Lefebvre, H. (1991). O direito a cidade. São Paulo: Moraes.

Ley $N^{\circ} 18595$. Otorga beneficio tributario para zonas de renovación urbana. Ministerio de Hacienda. Santiago, Chile, 27 de enero de 1987.

Matesanz, Á. (2016). Politicas urbanas y vulnerabilidad. (Tesis doctoral Arquitectura, Universidad Politécnica de Madrid, Madrid). Recuperado de http://oa.upm.es/44893/

Michelin, J. (2019). La metrópolis creativa. Innovaciones sociales en América Latina y el sur de Europa. Madrid: Catarata.
Real Academia Española. (2020). Diccionario de la lengua española. Recuperado de https://dle.rae.es/

Rojas, E., Rodríguez, E., y Wegelin, E. (2004). Volver al centro, la recuperación de áreas urbanas centrales. Washington: BID.

Schritt für Schritt. Behutsame Stadterneuerung in Kreuzberg. (1990). Berlín: STERN.

Schubert, D. (1998). Von sanierenden Wiederaufbau zur nachhaltigen Stadterneuerung. Kontinuitäten und Paradigmawechsel. En Jahrbuch Stadterneuerung 1998 (pp. 125-139). Berlin: Technische Universität Berlin

Segado-Vázquez, F. y Espinosa-Muñoz, V. (2015). La ciudad herida. Siete ejemplos paradigmáticos de rehabilitación urbana en la segunda mitad del siglo XX. EURE, 41(123), 103-129. https://doi.org/10.4067/S0250-71612015000300005

Smith, A. (2012). Events and urban regeneration. The strategic use events to revitalize cities. London: Routledge.

Sorando, D. y Ardura, A. (2016). First we take Manhattan. La destrucción creativa de las ciudades. Madrid: Catarata.

Spatial development glossary. (2007). Strasbourg: Council of Europe Publishing.

Suárez Pareyón, A. (1978). La colonia Guerrero, un caso de deterioro urbano (tercera parte). Arquitectura Autogobierno, (9), 36-44. 


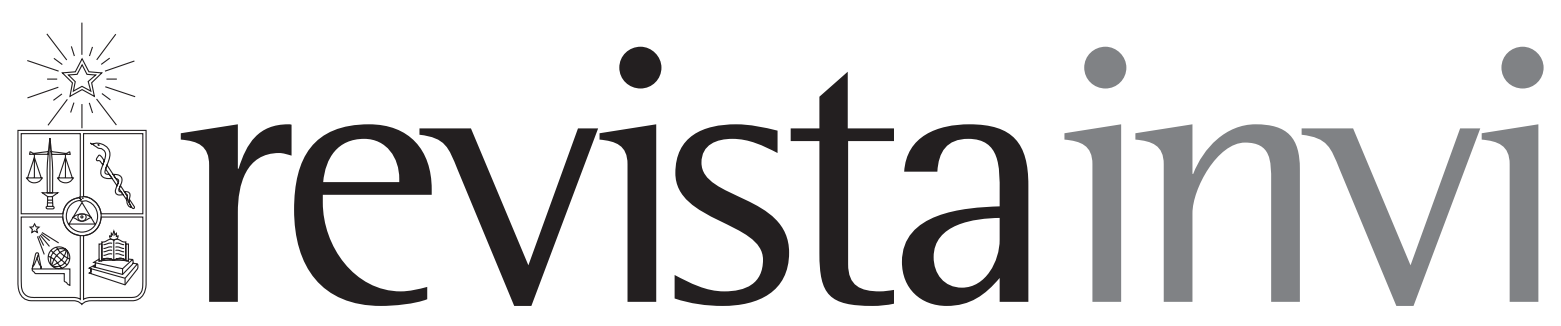

Revista INVI es una publicación periódica, editada por el Instituto de la Vivienda de la Facultad de Arquitectura y Urbanismo de la Universidad de Chile, creada en 1986 con el nombre de Boletín INVI. Es una revista académica con cobertura internacional que difunde los avances en el conocimiento sobre la vivienda, el hábitat residencial, los modos de vida y los estudios territoriales. Revista INVI publica contribuciones originales en español, inglés y portugués, privilegiando aquellas que proponen enfoques inter y multidisciplinares y que son resultado de investigaciones con financiamiento y patrocinio institucional. Se busca, con ello, contribuir al desarrollo del conocimiento científico sobre la vivienda, el hábitat y el territorio y aportar al debate público con publicaciones del más alto nivel académico.

Director: Dr. Ricardo Tapia Zarricueta, Universidad de Chile, Chile.

Editor: Dr. Luis Campos Medina, Universidad de Chile, Chile.

Editor asistente: Dr. Walter Imilan, Universidad de Chile, Chile.

Coeditora: Srta. Sandra Rivera, Universidad de Chile, Chile.

\section{COMITÉ EDITORIAL:}

Dr. Victor Delgadillo, Universidad Autónoma de la Ciudad de México, México.

Dra. María Mercedes Di Virgilio, CONICET/ IIGG, Universidad de Buenos Aires, Argentina.

Dra. Irene Molina, Uppsala Universitet, Suecia.

Dr. Gonzalo Lautaro Ojeda Ledesma, Universidad de Valparaíso, Chile.

Dra. Suzana Pasternak, Universidade de São Paulo, Brasil.

Dr. Javier Ruiz Sánchez, Universidad Politécnica de Madrid, España.

Dra. Elke Schlack Fuhrmann, Pontificia Universidad Católica de Chile, Chile.

Dr. Carlos Alberto Torres Tovar, Universidad Nacional de Colombia, Colombia.

Sitio web: http://www.revistainvi.uchile.cl/

Correo electrónico: revistainvi@uchilefau.cl

Licencia de este artículo: Creative Commons Atribución-Compartirlgual 4.0 Internacional (CC BY-SA 4.0) 